\title{
PREFACE TO THE FIRST EDITION
}

This is a book about how to make and implement land use decisions. It seeks to develop a set of coherent planning principles by drawing out useful and generally applicable elements from the various systems and approaches. It makes assumptions about what land use planning is supposed to do and what elements in existing theories and practices can be useful in this pursuit. It is not a report or a critique but a guide for practice.

The focus is on planning at the city level. It is addressed to planners who make and implement plans, to politicians and administrators who legitimize and supervise them, to developers and property owners whose actions and decisions are conditioned by them, and to specific groups and the general public whose welfare and quality of life are affected by them. Through a shared understanding of the purpose, analytic skills and substantive considerations of plan-making, and the ways and means of plan-implementation, both the planner and the planned may become more responsible and responsive in using our land to satisfy the many human needs.

In writing this book, I borrowed heavily, both in style and substance, from four sources: Lewis Keeble's Town Planning Made Plain, Sebastian Loew's Local Planning, Chapin and Kaiser's Urban Land Use Planning, and Kevin Lynch's Site Planning. I hope the authors consider my effort has been worthwhile. 